


\title{
Constitucionalismo y democracia: análisis desde el caso colombiano en los 30 años de la expedición de la constitución de 1991*
}

\section{Yenny Andrea Celemin Caicedo**}

\section{Resumen}

El artículo hace un balance de la propuesta de la Constitución Colombiana de 1991 en relación con las instituciones de gobierno representativo y de sus diversas reformas durante los últimos 30 años. El propósito de este examen es analizar los efectos de la falta de atención que el constitucionalismo colombiano le ha puesto a la democracia, específicamente, para comprender lo que realmente ha sucedido con su reconfiguración y su nueva apariencia. El escrito sostiene que se trata de una democracia que ya no luce como democracia parlamentaria, tal y como fue originalmente pensado por los constituyentes de 1991, sino que desde las reformas subsiguientes ha avanzado a la modalidad de democracia de partidos.

Palabras claves: democracia representativa en la Constitución de 1991; reforma política de 2003; reforma política de 2009; reforma política de 2015

\section{Constitutionalism and democracy: analysis from the colombian case since the 30 years of the enactment of the 1991 constitution}

\begin{abstract}
This article evaluates the 1991 Colombian Constitution proposal in relation to the representative government institutions and its several reforms during the past 30 years. The purpose of this examination is to analyse the effects of the lack of attention of the Colombian constitutionalism for understanding what has in reality happened with the realignment and new face of democracy in Colombia. A democracy that no longer looks like a parliamentary democracy, as was originally thought by the 1991 constituents, but that has transformed to the modality of the democratic party due to subsequent reforms.

Keywords: Representative Democracy in the 1991 Colombian Constitution; 2003 Constitutional amendment; 2009 Constitutional amendment; 2015 Constitutional amendment.

\section{Constitucionalismo e democracia: analise desde o caso colombiano nos 30 anos da expedição da constituição de 1991}

\section{Resumo}

0 artigo faz um balanço da proposta da Constituição colombiana de 1991 em relação com as instituições de governo representativo e de suas diversas reformas durante os últimos 30 anos. 0 objetivo dessa análise é avaliar os efeitos da falta de atenção do constitucionalismo colombiano à democracia, especificamente para compreender o que realmente aconteceu com sua reconfiguração e sua nova aparência. 0 texto sustenta que se trata de uma democracia que já não se visualiza como democracia parlamentária, exatamente como foi originalmente pensada pelos constituintes de 1991, já que desde as reformas subsequentes, chegaram à modalidade de democracia de partidos. Palavras-chave: Democracia Representativa na Constituição de 1991; Reforma Política de 2003; Reforma Política de 2009; Reforma Política de 2015.

* Artículo de reflexión. Derivado del trabajo como miembro del grupo de investigación de derecho público de la Universidad de los Andes.

** Profesora Asistente, Facultad de Derecho, Universidad de los Andes, Colombia. PhD en Derecho Universidad de los Andes. Email: ya.celemin24@uniandes.edu.co. ORCID: https://orcid.org/0000-0002-3308-0129.

Cómo citar este artículo: Celemin Caicedo, Y. A. (2021). Constitucionalismo y democracia: análisis desde el caso colombiano en los 30 años de la expedición de la constitución de 1991. Estudios de Derecho, 78 (172), 220-249 


\section{Constitucionalismo y democracia: análisis desde el caso colombiano en los 30 años de la expedición de la constitución de 1991}

\section{Introducción}

Colombia como muchos de los países occidentales contemporáneos puede clasificarse como una democracia constitucional. Las democracias constitucionales son una fórmula de organización política e institucional que se caracterizan por la interacción de diversos poderes públicos, algunos de los cuales han sido elegidos democráticamente. Estos poderes se encargan, entre muchas otras tareas, de la regulación de las actividades al interior de las comunidades nacionales bajo la égida de una Constitución (Habermas, 2000; Salazar, 2006).

Muchos constitucionalistas estarán de acuerdo con la idea que las dos partes del metaconcepto de democracia constitucional se cataloguen como "eslóganes abstractos" (Mendes, 2013, p. 16). Aquí, se quiere adicionar algo más. Aunque constitucionalismo y democracia son "eslóganes abstractos", el derecho constitucional, por lo menos en Colombia, ha sido bastante cuidadoso en dar forma, delimitar y comprender la tradición, las características, los principios y las instituciones de uno de estos dos eslóganes: el del constitucionalismo. Del mismo modo, la preocupación por dar forma, delimitar y comprender la tradición, las características, los principios y las instituciones de la democracia presentan un profundo déficit, por lo menos cuando uno se sitúa desde la disciplina jurídica.

El tratamiento exhaustivo que se le da a la noción de constitucionalismo, destaca los más importantes detalles y fundamentos de este concepto. En este orden de ideas hay una generalización de la comprensión del constitucionalismo como un área de estudio relacionado solo con los derechos fundamentales y con los elementos necesarios para salvaguardarlos, tales como la rigidez y el control constitucional (Bayón, 2010, p. 287). Este encuadramiento se ha convertido en una fórmula axiomática, que es necesario aprender y diferenciar en la disciplina jurídica desde las primeras clases de derecho constitucional.

En contraste, este interés o entusiasmo decrece cuando se trata de enunciar o discutir alguna fórmula axiomática sobre la democracia o alguna postura 
dogmática sólida sobre la materia. La única proposición que se ha venido incluyendo en los manuales de derecho constitucional sobre la democracia en nuestro contexto académico es su comprensión como "el gobierno del pueblo" (Herrera, 2011; Molina y Perdomo, 2005; Pérez, 2010). Pero esta proposición no suscita en nuestra disciplina mayores reflexiones o discusiones. Estos conceptos se abordan como si se tratara de una cuestión que se encuentra en las fronteras del área jurídica. Muchas veces, ni siquiera alcanza el status de algo digno de ser tratado por el derecho y debe buscar su nicho por fuera de él, más bien en disciplinas como la Ciencia Política.

Es común que los trabajos del derecho constitucional en Colombia excluyan como temas de estudio o de descripción, análisis rigurosos sobre los procesos de autorización electoral ${ }^{1}$ a través de los cuales se conforman las instituciones legislativas; análisis que den cuenta de la complejidad, las transformaciones y las problemáticas que caracterizan el régimen electoral en Colombia. Igualmente, los temas relacionados con la democracia y su conexión con las instituciones representativas, a pesar de su importancia, frecuentemente están excluidos de los programas del área de derecho constitucional de muchas universidades del país.

Esta falta de atención del eslogan de la democracia conduce a generar una reflexión que permite dilucidar interrogantes relacionados con la manera cómo ha venido cambiando la propuesta original de 1991, en relación con la democracia representativa en Colombia. Aquí se va se va a sostener que, de una propuesta basada en la comprensión de una democracia liberal de tipo parlamentario, las instituciones representativas en Colombia han dado un viraje hacia una democracia de partidos. Esta modificación de la propuesta original se ha consolidado a partir de las múltiples reformas que ha sufrido este elemento de nuestra democracia constitucional. Para sostener esta tesis el artículo se va a dividir en dos partes. En la primera parte, se van a elaborar algunas reflexiones correlacionadas con la forma como se han abordado la relación entre el constitucionalismo y la democracia en el contexto colombiano. En la segunda parte, el artículo se va a centrar en la democracia representativa, para efectuar una revisión de la literatura y de normas constitucionales con el propósito de evidenciar el desarrollo este tipo de democracia dentro de la Constitución de 1991.

\section{La relación entre el constitucionalismo y la democracia en el derecho constitucional colombiano}

El desequilibrio en el tratamiento del concepto de democracia constitucional, gracias al cual, el derecho constitucional ha estado llenando de contenido el eslogan

1 Por el proceso de autorización electoral se entiende el conjunto de reglas que permiten el desarrollo de elecciones, libres y justas que son adelantadas en intervalos regulares (Manin, 2008, p. 20). 
de constitucionalismo y ha dejado a la democracia reducida a la categoría de "eslogan abstracto", puede tener al menos dos explicaciones en nuestro contexto. En seguida se describen estas preferencias.

\subsection{La preferencia del derecho constitucional colombiano por la democracia en su modo sustantivo a partir de la expedición de la Constitución de 1991}

En este documento se quiere argumentar que, con el advenimiento de la Constitución de 1991, el derecho constitucional colombiano ha estado fuertemente ocupado en llenar de contenido el eslogan de constitucionalismo y por esto mismo, no ha tenido la oportunidad de revisar profundamente, los contornos de la democracia y de sus relaciones con las instituciones representativas. Así mismo, la mayoría de los trabajos que articulan estos temas tienen algo en común: en ellos se está dialogando desde un concepto sustantivo de democracia, en lugar de hacerlo con un concepto procedimental robusto de democracia. En esta manera de entender la democracia, además de la existencia de una competencia electoral que produzca cambios en las personas, en el gobierno y en las políticas respetando las reglas y sin que medie el ejercicio de la violencia (Pzreworski, 2010), la democracia requiere de algo adicional. Es necesario que se prediquen límites a estas personas, a estos gobiernos y a estas políticas sobre "lo que no se puede decidir, pero muy especialmente sobre lo que se puede decidir" (Ferrajoli, 2011, p. 211). Esta forma de entender la democracia se denomina como democracia sustantiva.

Ahora bien, no se considera que esta sea una tendencia irracional o inexplicable. La fuerza con la que se ha desarrollado esta forma de análisis en Colombia está directamente conectada con la manera como la Constitución de 1991 rompió con algunas manifestaciones de la cultura legalista en el pensamiento jurídico colombiano. Las formas de comprender el derecho más allá de los textos legales y de incorporar principios en el proceso de interpretación judicial, del papel de los jueces como intérpretes de la Constitución o de la posibilidad de reclamar en sede judicial los derechos fundamentales, son factores que han impactado en muchas formas las realidades políticas y sociales en el país.

Utilizando una metáfora, es posible comparar el ejercicio de análisis que hace la dogmática constitucional con el ejercicio de conducir un automóvil. En efecto, esta dogmática parece conducir el automóvil mirando preferiblemente uno solo de los espejos del vehículo: el espejo que mira hacia el lado del constitucionalismo. En este orden de ideas, el conductor, que sería el dogmático, no muestra mayor interés en mirar el espejo que ve hacia el lado de la democracia. Sin embargo, en una democracia constitucional es importante que el conductor mire hacia ambos espejos. Es importante, que la dogmática constitucional también analice los planos relacionados con el momento de aplicación de la Constitución, cuando las instituciones del gobierno representativo son autorizadas para elaborar normas jurídicas. 
Es decir, la dogmática constitucional también debe decir algo de la democracia en su modo procedimental y no solo en su modo sustantivo.

Cuando la democracia es entendida en su modo procedimental, la preocupación del constitucionalismo es otra. Aquí, el constitucionalismo no se enfoca tanto en el momento de creación cuando las legislaturas crean/aplican derecho, sino que el foco de atención se centra en los análisis sobre el momento de aplicación del derecho de la Constitución, cuando las legislaturas hacen este mismo proceso (Kelsen, 2001). En esta visión de democracia procedimental el constitucionalismo se debe hacer preguntas sobre cómo se desarrollan los procedimientos democráticos el día de las elecciones y los días subsiguientes, además de las preguntas sobre qué tipo de límites no pueden traspasar las instituciones democráticas cuando crean y aplican derecho.

Para una definición mínima de democracia -como la que estudiamos aquí- [...] se precisa además del sufragio universal y del principio de mayoría una tercera condición: es necesario que los llamados a decidir o a elegir a aquellos que deberán decidir, sean colocados frente a alternativas reales y puestos en condiciones de poder elegir entre una y otra. Para que se realice esta condición es necesario que los llamados a elegir se les garanticen los derechos de la propia opinión, de reunión, de asociación, etc. [...] Las normas constitucionales que atribuyen estos derechos no son propiamente reglas del juego: son reglas preliminares que permiten el desarrollo del juego. (Bobbio, 2005, p. 5)

Sin embargo, en muchas ocasiones el derecho constitucional en Colombia comprende la democracia procedimental como una idea simple, una idea a partir de la cual en el juego de la democracia "todo se vale" ${ }^{2}$. Sin embargo, la democracia procedimental no es esto. Diversos autores trabajan perspectivas robustas de la democracia procedimental en la que inclusive hay muchos espacios y consideración al tema de los derechos ${ }^{3}$. En este punto, es preciso señalar que las concepciones procedimentales robustas y las concepciones sustantivas de democracia están de

2 Aquí quiero hacer referencia al tratamiento que un autor de gran influencia en el derecho constitucional en Colombia hace sobre las concepciones de democracia procedimental, el trabajo de Luigi Ferrajoli. De acuerdo con este autor: "Para la supervivencia de la cualquier democracia es necesario la existencia de cualquier límite sustancial. En ausencia de tales límites, relativos a los contenidos de las decisiones legítimas, una democracia no puede o -al menos puede no- sobrevivir. En línea de principio, siempre es posible suprimir, por mayoría, los derechos de libertad e inclusive el derecho a la vida. Más aún: es posible democráticamente, es decir, por mayoría, suprimir los mismos derechos políticos, el pluralismo político, la división de poderes, la representación, en una palabra, todo el sistema de reglas en el que consiste la democracia política. No hablo de hipótesis de escuela: aludo a las terribles experiencias totalitarias del siglo pasado, cuando el fascismo y el nazismo se adueñaron del poder en formas democráticas para atribuírselo 'democráticamente' a un jefe que suprimió la democracia”' (Ferrajoli, 2011, p. 245).

3 Sobre el particular se deben mencionar a autores como Norberto Bobbio, Michel Angelo Bovero, Carlos Santiago Nino, Jeremy Waldron, Hans Kelsen, Juan Carlos Bayón, Juan Jaramillo (Q.E.P.D.), Floralba Padrón, David Roll, entre otros. 
acuerdo en una idea básica: democracia y constitucionalismo se pueden reconciliar sí se toma en consideración que ciertos derechos imponen limitaciones a la democracia. Ahora bien, a pesar de la sintonía de estas concepciones en relación con la existencia de estos límites, las concepciones procedimentales y sustantivas de democracia están en desacuerdo en algunos aspectos: (i) ¿Hasta dónde van estos límites?, y, sobre todo, (ii) ¿Quién, en una democracia constitucional, está habilitado o mejor situado para tomar las decisiones sobre estos límites? ${ }^{4}$. En el constitucionalismo colombiano hay un déficit de autores que trabajen a partir de una perspectiva que comprenda la democracia desde el plano procedimental robusto. Por este motivo, hay desinterés en entender las respuestas a las preguntas propias de esta forma de aproximación a la democracia.

\subsection{La preferencia del derecho constitucional en Colombia por la democracia en su modo participativo a partir de la Constitución de 1991, en lugar de, en su modo representativo}

Una segunda manera en la que se manifiesta el desequilibrio en el tratamiento del concepto de democracia en Colombia, tiene que ver con el interés hacia los adjetivos participativo y social para calificar el concepto de democracia. Esto en contra de la utilización de los adjetivos representativo y liberal para definir este concepto:

La participación ciudadana adquirió en las últimas dos décadas un peso significativo en el diseño de los sistemas democráticos, como respuesta a las debilidades del modelo hegemónico de democracia liberal representativa que dominó el panorama político en occidente en los últimos dos siglos. (Hurtado e Hinestroza , 2016, p. 64)

De acuerdo con este enfoque, no es necesario prestar atención a los principios, instituciones y características de la democracia en la forma del gobierno representativo, porque esta forma será considerada como una "falsa democracia" (Manin, 2008, p. 11).

Una tendencia creciente del derecho constitucional en Colombia ha estado perdiendo el interés por esta "falsa democracia”, al sentir una fuerte atracción hacia modelos más "prometedores" de democracia: "Como la democracia representativa se volvió vulnerable, además a los intereses del mercado económico y político, cada vez más juntos y promiscuos, la democracia participativa puede traer otros

4 En el contexto global, las respuestas a estos interrogantes han propiciado un debate entre dos autores de muchos quilates. Una primera respuesta a este interrogante es la sostenida por Dworkin. Su respuesta, construida desde una perspectiva sustantiva de democracia, sostiene que los jueces están mejor situados para determinar los límites sobre la política. Por el contrario, y desde un punto más procedimental de democracia, Jeremy Waldrón ubica a los legisladores como los agentes que tienen una mejor posición para adoptar esta clase de decisiones. 
valores de cooperación y solidaridad" (Cruz y Real , 2010, p. 25). Esta literatura se ha enfocado en ofrecer una panorámica desalentadora sobre las instituciones del gobierno representativo y presentar un enfoque cargadamente pesimista acerca del proceso de representación:

En Colombia, la crisis de la representación política que se manifiesta como desarraigo social a lo político, parece más acentuada que en otras partes. Colombia ha sido durante mucho tiempo un país político en donde las afiliaciones, las sensibilidades, las clientelas se han construido mediante la relación con los partidos políticos. Incluso la extrema izquierda, agrega Pecault se ha entregado a su manera a una hiperpolitización, y poco se preocupado por las demandas sociales de la población. (García y Revelo, 2009, p. 28)

Según este enfoque, pareciera que los graves problemas del proceso de representación en Colombia, a causa de factores como la violencia y la presencia de los grupos armados en los procesos de elección, deberían conducir a cerrar la página de análisis de la representación. Este ejercicio de elusión se basa en una idea: la democracia solo tiene una cara que es real y a su vez trasformadora. Sin las contradicciones y las cortapisas del liberalismo, ni las deficiencias o limitaciones del proceso de representación, la democracia se presenta únicamente, cuando ella se describe como participativa o social. Adicionalmente, el interés del constitucionalismo por las características y las instituciones de la democracia con sus adjetivos, bien sean participativa o bien sea social, no solo se explica en el argumento de la crisis de la representación. El impacto de las instituciones de la Constitución de 1991 y la acción de tutela para explicar esta estrategia es innegable. El rol de la Corte Constitucional para materializar los derechos y dar agencia a movimientos sociales históricamente discriminados o socialmente marginados, ha desempeñado un papel sumamente importante en este proceso ${ }^{5}$.

En esta estrategia, una porción importante de la dogmática constitucional ha decidido ignorar el espejo que mira hacia la democracia (representativa) para ver hacia el frontal que muestra un camino más directo a la defensa y protección de los derechos de los ciudadanos. En esta estrategia como consecuencia de los problemas del espejo (porque está roto, porque distorsiona lo que verdaderamente hay en la vía o porque se lo robaron en la contienda electoral anterior), el conductor (que en nuestro caso será el dogmático), ya no quiere ni mirar a las instituciones

5 Incontable es la literatura que ha observado la manera como la simplicidad procesal y universalidad de mecanismos de participación popular, como la acción pública de inconstitucionalidad o la tutela, han facilitado que "muchos sectores de la sociedad colombiana perciban en las decisiones de la Corte un poco de oportunidad real para verdaderamente proteger sus derechos" como una solución ante la grave crisis del proceso de representación, la democracia participativa se erige como la única forma de garantizar algún margen de acción a los ciudadanos" (Uprimny \& García, 2005, p. 81). 
del gobierno representativo. La cuestión es que ya ni siquiera hay un interés de mirar ese espejo disfuncional, aun cuando sea para ver cómo lo componemos. Nohelen (2009), considera este como un problema común del discurso sobre la democracia en América Latina:

El segundo desafío [de la democracia] reside en la reforma de las instituciones políticas para generar más transparencia y más responsabilidad (accountability), en términos verticales en su relación con el electorado, como horizontales entre los órganos representativos y de control de gobierno. Se observa que en el discurso político en América Latina se atiende más a la participación. Sin embargo para el encausamiento de la democracia (estructuración y canalización), las instituciones son indispensables tanto como su reforma, para aumentar la gobernabilidad. (Nohelen, 2009, p. 29)

Hay varios problemas que se derivan de ver la representación de una manera tan pesimista. El primero de ellos es que esta perspectiva no toma en consideración muchas variables, entre ellas, que en nuestro país actúan personas y se producen decisiones bajo los marcos y parámetros de actuación de las instituciones representativas. Autores como Farber (2006), por ejemplo, han notado esta misma situación en el derecho constitucional de los Estados Unidos. En efecto, Farber cuestiona que a pesar de la supremacía que tiene la Corte Suprema de los Estados Unidos, hay una serie de espacios de regulación en los que el órgano legislativo de este país es el que confecciona y da sentido a la Constitución. La determinación de la estructura administrativa del Estado, el diseño y modificación de las normas electorales, y las modificaciones a la Constitución mediante actos legislativos son algunas de las decisiones de las que frecuentemente se encargan las legislaturas. Por este motivo, este autor señala que "hasta en los sistemas retratados como sistemas de supremacía judicial, las legislaturas continúan teniendo un significativo rol constitucional" (Farber, 2006, p. 449).

Adicionalmente, una alerta que vale la pena poner de presente, es que la crítica a la democracia representativa parece dejar de lado que la democracia, en su formulación bien sea participativa o social, también presenta limitaciones como forma de tomar decisiones políticas en sociedades pluralistas y complejas como las sociedades modernas. Sobre el particular enfatiza Nino (1997):

Debemos detenernos con cuidado a considerar las diferencias que existen entre formas de democracia directa y la práctica de la discusión moral ideal. A pesar de que las primeras implican la expresión directa de las opiniones de los votantes respecto de cuestiones políticas o de la gestión de los funcionarios públicos, ellas no reflejan una discusión genuina. Los participantes sólo pueden decir sí o no. (...) En una discusión los propios participantes son los que formulan 
las preguntas, expresan sus intereses y tratan de justificarlos frente a los otros. (p. 210)

Ahora bien, parece que la estrategia de eludir la ambigüedad de la idea de democracia puede hacerse extensiva a otras latitudes tal como lo reclamó enconadamente Giovanni Sartori:

Mientras que las soluciones simplistas ideadas por la imagination au pouvoir se disolvieron por sí solas, su herencia permanece entre nosotros en forma de negativismo simplista. Tantas cosas marchan mal en el mundo real que no es posible equivocarse si se sigue el camino de la crítica. El resultado neto del simplismo y la democracia infantil es que la vieja maquinaria de la política recibe muchos garrotazos, sin que nada se diga de la forma en que se puede componer o mejorar. De hecho, cuanto más la ataquemos, menos seremos capaces de repararla. Por esa misma razón, hemos dedicado todo nuestro ingenio a la democracia horizontal y en el proceso no sólo no hemos descuidado sino ridiculizado la democracia vertical, lo que equivale a decir que durante varias décadas aparentemente hemos olvidado y ciertamente ignorado, que al final de cuentas, democracia es, y no puede evitar ser, un sistema de gobierno. (Sartori, 2000, p. 160)

Aquí no se quiere sostener que reestablecer el equilibrio en la descripción de democracia constitucional en Colombia implique desatender o criticar (como si lo hace directamente Sartori) las manifestaciones de la democracia en su modo participativo o social. Sin embargo, se considera que también es necesario que el constitucionalismo en Colombia se detenga a analizar, con la misma preocupación y profundidad, las instituciones, características y principios que acompañan a la democracia cuando esta se complementa con el adjetivo representativo. Vale la pena empezar a preguntarse más sesudamente porqué razón está el espejo roto, qué parte de la realidad está distorsionando este espejo y, lo que es más importante, cómo podemos repararlo para que el gobierno representativo en nuestro país pueda llamarse, con toda autoridad, como gobierno democrático, y no solamente como a manera de eslogan.

\subsection{Las consecuencias de las preferencias del constitucionalismo en sus análisis sobre la relación entre el constitucionalismo y la democracia}

En Colombia es grande el contraste de obras, de autores o de investigaciones que se han preocupado por llenar de contenido el eslogan de constitucionalismo con el conjunto de obras, autores o investigaciones que se han preocupado por llenar de contenido el eslogan de la democracia. Para explicar esta idea, invito al lector a que imagine que el derecho constitucional es algo parecido a un mapa que mues- 
tra una serie de representaciones sobre el terreno para orientarnos hacia uno u otro destino. Estas representaciones tienen propósitos distintos, que van desde comprender o proponer teorías sobre la forma como se comporta el terreno (si es curvo, si es plano, si debemos a travesar o rodear una montaña, si es estable o inestable), hasta finalidades más prácticas como la forma de llegar a un lugar a otro y de interpretar las pistas ofrecidas por el mapa.

Aquí se ha estado argumentando que la dogmática del derecho constitucional ha estado utilizando una cartografía poderosa para describir el territorio y los destinos a los que se pueden llegar si se conduce por el lado del constitucionalismo. En otros términos, el derecho constitucional en Colombia ha venido elaborando excelentes mapas sobre el constitucionalismo, sus características y sus instituciones. Esta solidez seguramente sirve como explicación a la proliferación de trabajos sobre estos aspectos que se ha dado en los últimos años. Sin embargo, un efecto inesperado de ello es que este lado del mapa ya empieza a lucir sobrecargado en sus representaciones y, si algún costo tiene esta sobrecarga, es que las nuevas cartografías comienzan a perder utilidad. Por el contrario, quienes necesitan dirigirse a distintos destinos por el lado de la democracia no tienen muchos mapas para consultar a la hora de emprender algún rumbo, especialmente, si quieren analizar el quehacer democrático de las instituciones del gobierno representativo. Como la falta de indicaciones en este campo es tan evidente, empezar a construir estas cartografías resulta un trabajo complejo y lento, debe tener una pretensión intermedia, si acaso la de empezar a identificar las escalas de los mapas con alguna precisión.

Ahora bien, la necesidad de determinar estas escalas en los mapas del lado de la democracia no implica el que se esté atacando o criticando las instituciones del constitucionalismo, o que con esta reflexión se pretenda desmontar o atacar lo avanzado en estos terrenos. Como sostiene Habermas, el constitucionalismo y la democracia no son principios contradictorios o en tensión, sino más bien principios co-originales (Habermas, 2000, p. 767). Pero esta idea de co-originalidad debe estar respaldada por descripciones poderosas de cada uno de estos eslóganes. El derecho constitucional colombiano debe avanzar hacia la realización de descripciones más completas para llenar de contenido el eslogan de democracia, sin que ello implique soslayar las descripciones que se han hecho por el lado de los mapas del constitucionalismo. Por este motivo, es necesario cambiar la perspectiva y empezar a equilibrar las cargas. De lo contrario, los diagnósticos sobre el constitucionalismo colombiano serán similares a las ideas recogidas por Rodrigo Uprimny en su balance sobre los logros, retrocesos y agenda pendientes de los 20 años de la Constitución de 1991:

El balance empírico en estos veinte años de la apuesta por combinar un constitucionalismo fuerte (...) Por el contrario, la innovación de- 
mocrática que pretendió impulsar la Constitución de 1991 ha tenido un resultado bastante pobre. Los mecanismos de democracia directa, como el referendo o las consultas ciudadanas, han tendido no solo poco uso, sino que en general han sido bastante polémicos tanto en el nivel nacional como local. (...) pero en cambio, en estos veinte años la democracia representativa tendió más bien al deterioro (...). (Uprimny, 2012, p. 51)

En efecto, el balance nada halagüeño que hizo el profesor Uprimny en el cumpleaños número 20 de la Constitución de 1991, aún parece ser adecuado y, para nada impertinente, en los tiempos actuales en los que estamos conmemorando las bodas de perla de la Constitución de $1991^{6}$. Sin embargo, los constitucionalistas tenemos que admitir que estas premisas de alguna forma hacen invisible nuestra responsabilidad como agentes del campo jurídico que, al operar sus preferencias, han descuidado la cartografía del lado democrático de la Constitución, especialmente, en su modo representativo. Este asunto no deja de resultar paradójico si se toma en consideración que los problemas de hace 10 años lucen aún con una semblante similar, pese a que la definición de los elementos de la democracia representativa, ha sido uno de los aspectos que más se ha transformado desde la propuesta original de los constituyentes de $1991^{7}$. Sobre este particular se ha señalado:

En las últimas tres décadas, Colombia ha sido terreno fértil para la discusión y adopción de reformas electorales a nivel constitucional, a través de cuatro refirmas constitucionales se han introducido importantes cambios al sistema electoral nacional sobre temas como: el régimen de los partidos políticos y la responsabilidad política de los mismos, la implementación del voto electrónico, y la adopción y posterior eliminación de la reelección presidencial inmediata, por sólo mencionar algunas de ellas. (Misión Electoral Especial, 2017, p. 19)

A este listado de temas subrayado desde la disciplina de la Ciencia Política hay que adicionar otros elementos importantes que han caracterizado esta vorágine reformista ${ }^{8}$. En este orden de ideas, la distancia que existe entre la Constitución

6 Diagnósticos más cercanos en el tiempo muestran los bajos niveles de legitimidad de las instituciones propias del sistema electoral y lo que es más grave: "Si bien es relativamente común que haya escepticismo frente a la política —no sólo en América Latina, sino en el mundo entero- en Colombia estos niveles de confianza no son sólo bajos, sino que han disminuido notablemente en los últimos años" (Misión Electoral Especial, 2017, p. 64).

7 Sobre este reformismo señala Quinche (2020): “Las reformas constitucionales introducidas al régimen electoral y sus instituciones. Estas reformas han ocurrido, en buena parte, con las modificaciones al régimen electoral colombiano, que hasta 2019 cuenta con doce enmiendas constitucionales" (p. 753).

8 Entre estos cambios se destacan: (i) los cambios más bien inestables en relación con las fórmulas para permitir la representación descriptiva de determinados grupos ciudadanos; (ii) los temas de reingeniería constitucional de los órganos electorales para delimitar una institucionalidad que vigile y controle los momentos preelectorales y poselectorales y también de las acciones constitucionales diseñadas para controlar la responsabilidad de los representantes; 
promulgada el 6 de julio de 1991 y la Constitución existente 30 años después es significativa para ciertos temas, pero es realmente abrumadora frente a los asuntos de configuración y consolidación de los distintos momentos del proceso de representación política, como la autorización electoral, la representación política y el control. Pero la obsesión por delimitar los contenidos del constitucionalismo continúa obviando los temas de la democracia, pese a que la misma idea de rigidez constitucional, una de las piezas centrales del propio concepto constitucionalismo, se ha puesto en Colombia en tela de juicio con todas estas reformas.

Explorar las causas de esta vorágine reformista sobre los asuntos relacionados con las instituciones representativas y determinar las razones por las cuales los diagnósticos sobre la democracia en Colombia aún presentan balances negativos, pese a los cambios, es una tarea que escapa, por razones de espacio, a esta reflexión'. Sin embargo, en lo que sigue, se delinean algunos de los contornos de estas reformas a la propuesta de 1991, con el propósito de identificar ciertas señales importantes que se deben tomar en consideración para construir una cartografía robusta del eslogan de la democracia representativa en Colombia.

\section{La propuesta original de 1991 para la democracia representativa en Colombia y sus reformas}

En este punto se analiza la propuesta original que contenía la Constitución de 1991 en términos de democracia representativa para su identificación y para la posterior detección de sus cambios más significativos.

\subsection{La propuesta original para la democracia representativa: la apertura política}

Una de las razones por las que se justificó la necesidad de modificar la Constitución de 1886 estaba fundada en renovar los vicios de la clase política tradicional:

Uno de los temas que llevó a que se consolidara el movimiento de la séptima papeleta y que presionó la convocatoria a una Asamblea

(iii) la realización de ciertas modificaciones en elementos del trámite legislativo para promover la deliberación y hacer eficientes los recursos parlamentarios. Entre estos, se destacan la conformación paritaria de las comisiones de conciliación que refleje igualdad entre el número de senadores y representantes, así como la incorporación del requisito del anuncio previo y del régimen de bancadas. Por último, (iv) la determinación de ciertas excepciones al principio bicameral con el que funciona el órgano representativo colombiano para la realización de funciones de control político derivadas de la figura de moción de censura.

9 Para quienes tengan interés en profundizar en la materia se recomienda el documento de la Misión Electoral Especial que se centra, principalmente, en detallar un conjunto de recomendaciones para cambiar los sistemas políticos y colombianos, pero que hace diagnósticos importantes sobre estas problemáticas. Véase: https://moe.org.co/wpcontent/uploads/2017/04/Libro-Reforrma-completo-2017-1-1.pdf 
Nacional Constituyente de 1991 fue la necesidad de poder reformar el Congreso. (...) Y es que uno de los factores que más afectaba la institucionalidad en Colombia era precisamente la gran inconformidad que sobre el Congreso de la Republica tenía la ciudadanía. Algunas de las causas que habían generado este malestar eran: (i) Negligencia e incapacidad en el cumplimiento de sus funciones constitucionales. (ii) Era el símbolo de la decadencia de las instituciones y la clase política dominante. (iii) Sus miembros no tenían credibilidad y su reputación era muy mala. (iv) Cada vez eran más los escándalos sobre como repartían becas, puestos, y auxilios a cambio de votos. (v) La Crisis del Congreso había creado la sensación de vivir bajo una monarquía presidencial de origen popular (Dangond-Gibsone, 2012, pp. 347-348).

Es por eso que durante el proceso constituyente de 1991 se discutió fuertemente uno de los más importantes problemas de la democracia representativa colombiana: la inexistencia de una oferta política adecuada y suficiente para la representación de los diversos actores sociales en el país, por lo cual la Constitución de 1991 tuvo "el propósito de abrir el espacio político a nuevos partidos y movimientos, para ponerle fin al monopolio que han ejercido los partidos Liberal y Conservador sobre la vida política del país" (Jaramillo, 2007, p. 77).

Ante esta panorámica, la nueva Carta se enfocó en el diseño de instrumentos encaminados a ampliar la oferta política para incluir aquellas demandas sociales históricamente excluidas del proceso de representación política y apostó por delimitar una democracia parlamentaria de corte más liberal. Esta propuesta pretendía modificar la vieja institucionalidad de la Constitución de 1886 (Gargarella, 2005) que, aunque también sería tipificable como democracia parlamentaria, estaba fundamentada en un elitismo político que imponía barreras de entrada considerables al mercado político. La propuesta de la Constitución de 1991 buscó dar un giro desde los modelos elitistas clásicos a modelos más conectados y cercanos a los ciudadanos. Este reingeniería le dio una impronta de democracia parlamentaria de corte liberal al diseño propuesto originalmente por la Constitución de 1991.

A partir de este diseño se cambiaron las reglas de composición del Senado para incluir una circunscripción de carácter nacional que facilitara la representación de intereses nacionales, al mismo tiempo que se disminuyeron los costos de entrada para ejercer el derecho fundamental a la representación política en calidad de elegido. Esta disminución no solo se evidenció en la exigencia de unos requisitos mínimos para participar en los procesos electorales para conformar el Senado y la Cámara de Representantes, sino también en la apertura a la representación descriptiva de minorías étnicas particulares. Lo anterior, mediante la conformación de las circunscripciones especiales que han permitido la representación de las diferencias en el seno de los cuerpos de representación política. 
Sin embargo, esta declaración de principios de la propuesta original se vio escasamente acompañada de reformas al sistema político y electoral que facilitaran la apertura de nuevos espacios a actores distintos a los tradicionales. Dentro del conjunto de las tímidas puntadas que se dieron en el marco de la propuesta original se tiene: (a) el reconocimiento de la autonomía de los agentes del sistema político (partidos, grupos y movimientos) en su organización; (b) la garantía de la apertura política a través de la obligación del Estado de contribuir con la financiación de las campañas electorales; y (c) el reconocimiento de garantías institucionales para los partidos de oposición. Adicionalmente, la propuesta también incluyó la pérdida de investidura como medio para controlar a los representantes, así como una nueva cara que pretendía dar autonomía e independencia a las autoridades electorales.

Pese a lo anterior, las innovaciones constitucionales para ampliar la oferta de los intereses a ser representados, prontamente comenzó a producir nuevas amenazas sobre el momento de autorización electoral del proceso de representación política. Además, estas innovaciones constitucionales tampoco atacaron de raíz los viejos vicios enquistados en el sistema electoral colombiano relacionados con la reducción de la libertad de los electores como consecuencia del ejercicio de la violencia, el clientelismo y la corrupción electoral, asuntos que parecieron conservar algún grado de inmunidad frente al nuevo diseño constitucional. Los fenómenos del paramilitarismo y el narcotráfico, así como las relaciones clienterales entre representantes y votantes continuaron asomándose como un problema relevante aún después de 1991 (García y Revelo, 2009). La nueva propuesta, entonces, se quedó corta en su vocación de transformación de las instituciones políticas colombianas (Ruiz, 2004, p. 163).

La preocupación por dar una apertura a un sistema político tradicionalmente cerrado, no estuvo acompasada con la búsqueda de alternativas de solución a los problemas de manipulación del momento de autorización electoral. Sobre este particular se puede señalar que fueron pocas las medidas de esta propuesta que buscaron contrarrestar la coerción de los electores como consecuencia de la violencia o el clientelismo. Dentro de las medidas aprobadas por el constituyente de 1991 para atacar los clásicos problemas del Congreso se destaca la eliminación de la figura de los auxilios parlamentarios ${ }^{10}$. Pero otras de las medidas planteadas

10 El verbo eliminar debe ser leído con atención en la medida en la que es posible que algunos de los aspectos centrales de la figura de los auxilios parlamentarios hayan reaparecido con nuevos ropajes el diseño institucional posterior a la promulgación de la Constitución de 1991 (Duque, 2011). Estas manifestaciones son en los llamados cupos indicativos. Sobre el particular ha comentado Juan Camilo Restrepo: “Voy a ocuparme de los 'llamados cupos indicativos', que se diferencian de los llamados auxilios parlamentarios en el sentido de que, en los primeros, a diferencia de los segundos, el parlamentario agraciado no crea a su antojo la partida de gasto, sino que la recibe ya creada presupuestalmente, pero como si fuera de su propiedad política. Es él quien la direcciona; es él quien define a qué alcalde (normalmente de su misma orientación política) le corresponde ejecutarla; a menudo postula quién habrá de ser el contratista o el interventor de la partida en mención; es él quien en síntesis se lleva los méritos políticos de su ejecución, aunque, repitámoslo una vez más: a diferencia del antiguo 'auxilio parlamentario', la apropiación presupuestal en el 'cupo 
durante el proceso constituyente para erradicar estas prácticas se quedaron a medio camino en el proyecto constitucional del 91 (Duque, 2011). La devolución de la iniciativa del Congreso en materias económicas, para eliminar los costos de transacción entre los intereses de los territorios y los del ejecutivo, la prohibición de la reelección indefinida de los Congresistas para debilitar sus redes clientelares, la imposición de mandatos obligatorios que posibilitaran la revocatoria de los congresistas como mecanismo de control, la consagración del voto obligatorio para aumentar los costos en la captura del sistema electoral, entre otras propuestas, no lograron, en su momento, ni en la actualidad, hacer parte del catálogo de remedios para solucionar los clásicos problemas de la época de autorización electoral en nuestro país ${ }^{11}$.

La academia colombiana ha construido pocas explicaciones sobre este fracaso de la propuesta de la Constitución de 1991. La más interesante de todas ha sido la ofrecida desde la historia por Ricardo Zuluaga (2008). De acuerdo con este historiador, las discusiones al interior de la Asamblea Nacional Constituyente en relación con la revocatoria del Congreso elegido en el año de 1990, y las disputas que posteriormente condujeron a inhabilitar a los miembros de la Asamblea Nacional Constituyente para postularse a las elecciones del Congreso de 1992, consumieron gran parte de la agenda y el ímpetu del proceso de renovación del órgano legislativo:

De tal suerte que la revocatoria del Congreso es una decisión que mirada desde la óptica de los años, parece haber constituido un gravoso error histórico, no solo porque este debate consumió una muy significativa porción de las energías del constituyente, sino también porque la historia ha venido a demostrar que fue una media inocua, porque nada impidió que el viejo Congreso se reprodujera y perpetuara las viejas y deleznables prácticas que tanto malestar generan y que tanto daño la hacen al auténtico espíritu de la Constitución. (Zuluaga, 2008, p. 150)

En este orden de ideas, la propuesta de la Constitución de 1991 se centró preferiblemente en ampliar el menú de opciones de los electores colombianos mediante la apertura del sistema político, sin prestar mayor atención a sus efectos y sin reparar en los detalles del diseño institucional. Por este motivo, esta propuesta

indicativo' no la crea el parlamentario (ya está creada de antemano en la Ley de Presupuesto): el parlamentario simplemente la orienta, la direcciona, y usufructúa los méritos políticos que se derivan de su ejecución. Queda convertido en un intermediario privilegiado de una o unas determinadas apropiaciones presupuestales" (Restrepo, 2014, párrs. 4-5).

11 Estas propuestas pueden consultarse en la Ponencia de la Asamblea Nacional Constituyente denominada: Estructura, Composición y Funcionamiento de Estado. Ponentes Hernando Yepes, Alfonso Palacio Rudas y Alfonso Galán Sarmiento. Disponibles en el Archivo General de la Nación, Sección República, Fondo, Congreso Legajo 335. 
fue reglamentada por la vieja clase política, pero "con rabia contra la Constitución" (Zuluaga, 2008, p. 151). Esa carga emotiva contra la propuesta pronto empezó a mostrar graves efectos en el sistema político y electoral colombiano que se concretaron en un crecimiento exponencial de agrupaciones con interés de presentarse en las contiendas electorales, situación que condujo a la fragmentación y no a la apertura de la representación del sistema político (Arévalo, Angarita y Jiménez, 2013; Battle y Puyana, 2013; Holguín, 2006; Parra, 2020; Quinche, 2009).

Este efecto se concretó, en la medida en la que la norma sobre partidos y movimientos políticos (Ley 130 de 1994) flexibilizó las condiciones de entrada a los procesos electorales de las nuevas organizaciones políticas, sin imponer ningún requisito legal significativo para limitar la búsqueda de la financiación estatal de las campañas. Dicha flexibilización, en un contexto de desregulación, condujo a una inusitada explosión de los actores dentro del sistema político con el sólo propósito de perseguir estos recursos económicos:

Sin embargo estas herramientas, y específicamente la figura de los avales, fue empleada como estrategia electoral que en un primer momento permitió sacar provecho de la misma, pero, paulatinamente degeneró en una indiscriminada repartición de avales, y fomentó la indisciplina tanto intrapartidista como partidista, mediante la puesta en escena de diferentes listas o agrupaciones electorales personales, que si bien no obtenían el aval de su partido, lo solicitaban a otra agrupación o partido que pudiera otorgárselo, o simplemente, montaban su propio movimiento o partido mediante cualesquiera de las diferentes opciones que la institucionalidad ofrecía. Hasta el punto que obtenían las firmas por diferentes medios, para presentarlas ante el CNE y de esta manera obtener la personería, con sus respectivas prebendas. (Franco y Clavijo , 2006, p. 18)

El concepto clásico de microempresa electoral que se había cimentado sobre la base de las relaciones de lealtad clientelar propias del cacicazgo ejercido por los líderes y gamonales de los partidos tradicionales a nivel territorial (Pizarro, 2001) fue variando a raíz del diseño institucional propuesto por la Constitución de 1991. Este diseño propició una mutación de estas microempresas, que pasaron de ser agencias de empleo a diversificar su portafolio a otro tipo de organización con un animus societatis distinto. Un animus centrado en la obtención de los recursos públicos de financiación de las campañas electorales. La débil institucionalidad creada por el constituyente de 1991 para realizar la inspección, la vigilancia y el control en el manejo de estos recursos se convertía en el caldo de cultivo perfecto para propiciar un sistema de incentivos que permitía la captura de recursos públicos, a través de las propias reglas del sistema electoral. Sobre este particular se ha comentado: 
Esta apertura a nuevos competidores y la minimización de los criterios para la creación de un partido hizo que se pasara del histórico bipartidismo a un multipartidismo que llegó a contar con más de 70 partidos con personería jurídica, de los cuales, de una elección a otra, surgían y morían decenas que presentaban listas tanto a nivel nacional como territorial. (Battle y Puyana, 2013, p. 76)

Así, los efectos adversos de la propuesta eran muy delicados, sin que fuese notable que ella realmente hubiera contribuido a la diversificación de los intereses y de las perspectivas políticas objeto de representación. La dura lección que había dejado el ideario de los constituyentes parecía indicar que más fraccionamiento no necesariamente conduciría a mayor representatividad.

Los problemas mencionados crearon la necesidad de empezar a intervenir la Constitución de 1991, intervención que continúa en la actualidad. A continuación, se muestran los puntos más gruesos de estas reformas.

\subsection{La reforma política del 2003: de la apertura política al fortalecimiento de los partidos políticos}

La propuesta de la reforma política de 2003 estuvo encaminada a modificar la democracia colombiana, para trasformar la propuesta original de los constituyentes. Una propuesta que se había basado en transformar a Colombia en una democracia parlamentaria del modelo elitista al modelo liberal, pero que, en el camino de su implementación, había presentado graves dificultades. Por esto, la nueva propuesta se centró en que nuestro sistema pasara de una democracia parlamentaria a una democracia de partidos (Manin, 2008). Autores como Manin han estudiado las diversas modificaciones del gobierno representativo. De acuerdo con su trabajo, las características de la representación han derivado en distintas fórmulas: la democracia parlamentaria, la democracia de partidos y, más recientemente, la democracia de audiencias.

Mientras que, en la democracia parlamentaria, en la que se puede situar la propuesta original de la Constitución de 1991, los representantes son elegidos en virtud de las relaciones personales que ellos, de forma individual, construyen con los votantes, en la democracia de partidos la autorización electoral esta mediada por los partidos políticos. Otra diferencia importante entre estas distintas manifestaciones del gobierno representativo está dada por el grado de autonomía de los representantes. De esta manera, mientras en la democracia parlamentaria, los representantes votan de acuerdo con su conciencia, en la democracia de partidos, el partido es el que tiene el liderazgo para la conducción de las votaciones al interior de los parlamentos (Manin, 2008, p. 287). En este orden de ideas, el espíritu de las reformas posteriores a la propuesta original ha estado dirigido a fortalecer 
los partidos políticos y a consolidar la democracia de partidos, como una nueva estrategia para cualificar el momento de autorización electoral en Colombia (Arévalo et al., 2013).

En esta nueva formulación, los partidos políticos fortalecidos lograrían una representación de las preferencias políticas más allá de las relaciones de intercambio entre favores y votos, característica de la política basada en el clientelismo. Sobre este particular se ha señalado:

La reforma de 2003 estableció una tensión entre los principios del régimen liberal clásico de representación con principios constitucionales democráticos por la imposición de las reglas de un estado de partidos: la transición del mandato representativo libre hacia el sistema de partidos, el momento actual del sistema de la representación política de Colombia está determinado por la convivencia y contradicción entre principios de representación liberal y principios de representación democráticos. (Padrón, 2012, p. 251)

Ante la captura de los escenarios de apertura por partidos ficticios o de papel, el fortalecimiento de los partidos políticos, que fue impulsado por la reforma política, se centró en precisas modificaciones al sistema electoral colombiano para poner remedios a estas problemáticas. En primer lugar, la reforma estableció la determinación de un umbral de $2 \%$ de la votación como requisito para conservar la personería jurídica y, por allí, acortar las vías de acceso non sanctas a los recursos de financiación estatal. En palabras de Duque (2011): "Esto afectó a muchas pequeñas agrupaciones políticas que debieron decidir desaparecer o agregarse a otros partidos" (p. 437). Esta medida, a su vez, estaba estrechamente conectada con la modificación de algunos aspectos del sistema electoral, mediante la implementación del sistema D’Hondt como método de asignación de curules en las corporaciones públicas, en lugar del sistema de cociente electoral o método, o de Hare que supervivió a las discusiones de los constituyentes de 1991. Sobre el anterior sistema se ha sostenido lo siguiente:

Hasta antes de la de puesta en vigencia del citado acto, la fórmula electoral acogida en el país era la fórmula de Hare, también conocida como sistema de cociente electoral y de residuo. Básicamente consiste en totalizar el número de votos válidos y dividirlo entre el número de escaños a repartir, para obtener de esta forma una cifra denominada cociente electoral. La asignación de los escaños se hace inicialmente entre las listas cuya votación haya alcanzado la cifra del cociente, entonces se procede a asignar los cargos con los residuos o cifras restantes a las demás listas. A este método Sartori lo denomina como de mayor residuo, y en su opinión favorece a los partidos pequeños. (Quinche, 2004). 
Por el contrario, la modificación al sistema D’Hondt significa que solo los partidos capaces de lograr un número mínimo de votos, denominado como cifra repartidora tienen la capacidad de obtener escaños dentro del Congreso. Como la financiación está ligada a la personería o a la obtención de los escaños en las células representativas (Ley 30 de 1994), los cambios en el sistema electoral menguan las posibilidades de constituir partidos de papel con el propósito exclusivo de hacerse a los recursos y dineros de financiación disponibles en el sistema.

Una medida adicional para acabar con los partidos de papel consistió en la conformación de listas únicas para presentarse a las contiendas electorales. Pero la medida de las listas únicas incluyó un componente que le daría la nueva vuelta a la erradicación de las prácticas clientelares: el voto preferente, el cual puede entenderse como un: "voto individual [que] les permite a los electores sentirse más cerca de sus candidatos, y a estos últimos, hacer propuestas específicas, pero a la vez conduce a una competencia intrapartidista que va en sentido contrario de fortalecer los partidos" (Wills, 2010, p. 39), por lo cual esta fórmula termina imponiendo una lógica de "canibalismo" al interior de los partidos (Misión Electoral Especial, 2017, p. 67).

Sin embargo, las limitaciones establecidas para terminar con los partidos de papel y referidas a las modificaciones que pretendían acabar con las microempresas electorales resultaban insuficientes para evitar la captura del sistema por parte de otros actores con animus societatis mucho más siniestros. En este orden de ideas, los agentes situados desde la ilegalidad podían continuar penetrando el sistema político bajo el parapeto de los nuevos diseños del sistema electoral. Lo anterior en la medida en la que estos agentes cuentan con fuentes inagotables de financiación, en razón de sus actividades ilegales.

En palabras de García y Revelo (2009): “Una vez que las mafias y los poderes intermedios ilegales capturan las instituciones, se crea una institucionalidad de hecho o híbrida, o a medio camino entre la ley y la realidad, o entre lo legal y lo ilegal" (p. 57). La bochornosa captura de los órganos de representación en nuestro país por parte de los grupos armados ilegales, conocida como la parapolítica o como la farcpolítica desde el extremo ideológico contrario, se vino a sumar a la ya clásica problemática de este momento de autorización electoral del proceso de representación. Sobre este particular se ha señalado:

El diseño constitucional e institucional prescrito por Colombia sique una doctrina liberal democrática; aun así, este diseño institucional no pudo prevenir la penetración de la violencia política y criminal. Esta ambivalencia fue terriblemente exhibida por los recientes desarrollos de lo que de forma insidiosa se ha conocido como el escándalo de la parapolítica. Esta paradoja da una excusa para la cuestión de porque estos patrones de abuso de poder persisten a pesar de un diseño institucional que puede prevenirlos. La investigación ha ubicado esto 
entre el contexto histórico de la insidiosa relaciones clientelistas que han minado el completo monopolio de la violencia por el estado y conducido a un equilibrio entre los grupos armados en la periferia de la política y en el centro de las instituciones políticas. (Boesten, 2014, p. 261) (2) $^{12}$

Por este motivo, una nueva reforma política tuvo que sumarse a la propuesta de la Constitución de 1991 y a la reforma política de 2003, se trató de la reforma política de 2009.

\subsection{La reforma política de 2009: la eliminación de los partidos con animus societatis conectados con la violencia armada ilegal}

Mediante la reforma política de 2009 se persiguieron diversos propósitos. De un lado, se continuó el camino trazado por la reforma de 2003 para fortalecer los partidos a través del debilitamiento de los partidos de papel, para lo cual se invadió la autonomía de estas organizaciones que se había conferido en la propuesta original de 1991. En efecto, la Ley 30 de 1994 y la Ley 616 de 2000 se caracterizan por tener regulaciones minimalistas de los partidos o, en palabras de otros autores, por ser regulaciones que plantean un: "escenario de excesiva libertad en el funcionamiento de los partidos” (Arévalo et al., 2013, p. 243).

En este orden de ideas, la nueva reforma constitucional se genera con el propósito de establecer una serie de limitaciones a partir del texto directo de la Constitución para hacer que los principios constitucionales también les sean aplicables a estas organizaciones políticas de índole privado. De esta manera, principios como el deber de presentar plataformas políticas, el fortalecimiento de la democracia interna, la moralidad, la transparencia, y la equidad de género se constituyeron en nuevas reglas del juego en torno a las cuales debía girar el sistema político colombiano. Por ejemplo, en relación con el tema de equidad de género se señaló que:

Entre las medidas se establece la licencia de maternidad como causal justificada de falta temporal dentro de las corporaciones de elección popular, y por otro lado se establece como principio rector, en la actuación de las organizaciones políticas, la equidad de género, lo que obligara a la inclusión de la mujer en sus cuadros directivos. Sin embargo, las reformas futuras deben promover la igualdad paritaria que es una exigencia de una sociedad democrática. Se deberá establecer medidas para la forma de confección de las listas, garantizar la participación de las mujeres por tramos en el orden interno de las listas, listas cremalleras o cualquier medida que haga efectiva la participación política de las mujeres. (Padrón, 2012, p. 256) 
Igualmente, la reforma política continúo con el propósito de debilitar los partidos de papel al aumentar el umbral hasta el $3 \%$. También mediante la inclusión de una causal de pérdida de personería jurídica, cuando estas organizaciones no celebren convención colectiva por un término superior a dos años. Así, las nuevas reglas del juego les imponen a los partidos políticos, movimientos y grupos significativos de ciudadanos unas cargas mínimas de funcionamiento, por lo cual la necesidad de desplegar una operatividad administrativa para conservar la personería desincentiva la utilización del sistema electoral con la única finalidad de perseguir beneficios económicos.

Sin embargo, el fortalecimiento y la democratización de los partidos políticos, como fórmula de fidelización de las preferencias electorales, más allá de las relaciones clientelares, ha empezado a producir, nuevamente, problemas de cierre del sistema. Lo anterior en la medida en la que:

Si bien el acceso a los recursos públicos debe estar reglamentado por unos principios de seriedad y cumplimiento (...), esta forma de repartir los fondos no permite ampliar el pluralismo político ni mejorar las capacidades de las organizaciones políticas más pequeñas para volverse más competitivas. (Misión Electoral Especial, 2017, p. 98)

En este orden de ideas, aún no se percibe un diseño que fortalezca los partidos en un contexto de democracia, pero que, simultáneamente, no ahogue el pluralismo y la apertura política.

Ahora bien, a la altura del 2009 estas consideraciones tenían que ceder ante propósitos más urgentes. Propósitos orientados a prevenir la captura de los órganos de representación por parte de los grupos ilegales en el futuro. Es por este motivo, que la reforma política de 2009 se centró en la incorporación de consecuencias jurídicas adversas a la existencia de vínculos electorales entre los partidos políticos y los grupos armados ilegales. De hecho, la Corte Constitucional colombiana estableció que este era el propósito fundamental de la reforma constitucional 2009:

El objetivo general de la reforma era (...), prodigar herramientas para impedir que la voluntad democrática del electorado resulte interferida por la actuación de los grupos ilegales. Los objetivos específicos de la enmienda eran: (i) impedir el ingreso de candidatos que tuvieren vínculos o hubieran recibido apoyo electoral de grupos armados ilegales; y (ii) disponer de un régimen preventivo y sancionatorio, tanto a nivel personal como de los partidos políticos, que redujera el fenómeno de influencia de los grupos mencionados en la representación ejercida por el Congreso. (Corte Constitucional, 2011. Sentencia C-490 de 2011) 
Dentro de los mecanismos sancionatorios determinados por la reforma política de 2009 y por la ley estatutaria que la desarrolló ( Ley 1475 de 2011), para menguar la influencia de los grupos ilegales en el sistema electoral colombiano son destacables tres principalmente: (i) la imposición de sanciones a los partidos por delitos cometidos por sus candidatos avalados y relacionados con la vinculación a grupos armados ilegales y actividades del narcotráfico, o de delitos contra los mecanismos de participación democrática o de lesa humanidad ${ }^{13}$; (ii) la prohibición expresa de financiación de campañas electorales con recursos derivados de actividades ilícitas o que tengan por objeto financiar fines antidemocráticos o atentatorios del orden público (art. 27 Ley 1475 de 2011) ${ }^{14}$; (iii) la creación de la figura de la silla vacía ${ }^{15}$.

En esta misma línea de la democracia de partidos, la reforma política de 2009 dio autorización al Legislador para configurar una serie de sanciones al accionar irregular de los partidos políticos, así estas actuaciones no estén conectadas con el tema de vínculos con grupos ilegales. La imposición de multas, de sanciones de devolución de recursos de financiación, o inclusive la pérdida de la personería jurídica en los casos de otras actuaciones irregulares en los momentos de autorización electoral y/o de representación política de los partidos, son detalladas en sus aspectos sustantivos en la Ley que desarrolló el Acto Legislativo 01 de 2009.

Sobre este nuevo modelo de responsabilidad hay que señalar que este tiene incluso un matiz más preventivo. Lo anterior al permitirse la revocatoria del acto de inscripción de la candidatura cuando el candidato avalado por un partido para presentarse a un cargo de elección popular, se inscriba estando incurso en una causal de inhabilidad comprobable con plena prueba, o mediante la trasgresión a la prohibición de la doble militancia. Sin embargo, aunque la Ley avanzó en la definición de las conductas objeto de reproche por parte del Consejo Nacional

13 Una sanción que implica la imposibilidad del partido para presentar candidatos para la siguiente elección en la misma circunscripción. También, la pérdida de personería jurídica, si por cuenta del descuento de los votos de estos candidatos, la organización termina con un número de votos inferior al del umbral (art. 12 núm. 6 Ley 1475 de 2011).

Esta prohibición a su vez se ve reflejada en la imposición de responsabilidad jurídica a las directivas de los partidos que pueden ser sancionados por permitir este tipo de vínculos para la financiación (art. 12 Ley 1475 de 2011).

Entendida desde la Ciencia Política como "el no reemplazo de los escaños que quedaran vacantes cuando un congresista perdiera la investidura por ser vinculado a un proceso penal por vínculos con actores armados ilegales y la pérdida del escaño para el partido)" (Duque, 2011, p. 448). Desde la disciplina jurídica, a su vez, la figura de la silla vacía se ha comprendido como "un castigo a las organizaciones políticas al no tener el debido cuidado al momento de otorgar el aval a sus candidatos" (Gómez y Hernández, 2020, p. 30). Este castigo implica una imposibilidad para que el partido pueda reemplazar en las células legislativas a quien tuviese una condena penal o una medida de aseguramiento por delitos relacionados con pertenencia, promoción o financiación a/o por grupos armados ilegales, de narcotráfico, delitos contra los mecanismos de participación democrática o de lesa humanidad o por doble militancia. En esta medida de un sistema de responsabilidad individual, como el que caracterizó la propuesta de 1991, en la que el mecanismo de control por excelencia era un mecanismo subjetivo como la pérdida de investidura, se pasa a un sistema diferente. Un sistema que traslada ciertos elementos de control y responsabilidad política y jurídica de los individuos representantes hacia los partidos y sus directivos. 
Electoral como autoridad electoral, aspectos de procedimiento y otras cuestiones estrechamente ligadas a la debilidad institucional de este órgano han impedido que se realice un control efectivo de estas conductas ${ }^{16}$. Un control que garantice y permita que las normas contenidas en la Ley 1475 de 2011 y en la reforma política de 2009 cumplan cabalmente con sus propósitos preventivos.

\subsection{La reforma política de 2015: ¿Se les fue la mano con el impulso reformista?}

Nuevamente, en el año 2015 se expidió una reforma constitucional en Colombia para continuar acentuando nuestro sistema como una democracia de partidos. En el marco de una reforma estructural del Estado denominada como de "equilibrio de poderes" se volvieron a proponer y también a reformar diversos aspectos relacionados con el funcionamiento de los cuerpos representativos en el país. Específicamente con elementos concernientes a la autorización y el control electoral. En relación con la autorización electoral, la reforma política de 2015 profundizó en la idea de la oposición política al otorgar curules directas en los cuerpos de representación política al candidato que le siga en votos al presidente y a su fórmula vicepresidencial, así como a los alcaldes y a los gobernadores (art. 1 Acto Legislativo 02 de 2015). Igualmente, en la línea de la propuesta original de la Constitución de 1991, esta reforma modificó nuevamente lo relacionado con la representación descriptiva para adicionar a los raizales de San Andrés dentro del conjunto de minorías políticas a ser representadas en las células legislativas de Colombia.

Sin embargo, la reforma del equilibrio de 2015 dejó incólumes algunos aspectos problemáticos del sistema electoral, como es el caso del voto preferente. Aunque el proyecto originalmente presentado para el trámite del Acto Legislativo pretendía su eliminación, esta no prosperó (Gaceta del Congreso n.․ 458, 2014, p. 4).

A manera de premio de consolación, la reforma de 2015 terminó incorporando ciertas claridades con relación a la forma como deben contarse los votos preferentes en las listas, ello con el fin de mostrar cierta sensibilidad con problemas constitucionales que habían emergido como consecuencia de los vacíos regulatorios frente a este tema ${ }^{17}$. Es por ello que el Acto Legislativo señala que: "los votos por el partido o movimiento que no hayan sido atribuidos por el elector

16 Sobre la debilidad institucional del Consejo Nacional Electoral se ha dicho recientemente: "Una de las mayores debilidades que tiene el sistema de financiamiento político en Colombia tiene que ver con la poca capacidad del CNE para aplicar controles y sanciones oportunas y ejemplarizantes por la violación a las normas de financiamiento político. Esta debilidad institucional se deriva de varias causas que ya fueron identificadas en el informe de recomendaciones sobre arquitectura institucional, a saber: conformación partidista del órgano electoral, falta de autonomía presupuestal, débil alcance territorial, ausencia de instrumentos para ejercer inspección y vigilancia, y falta de personal idóneo para adelantar las investigaciones" (Misión Electoral Especial, 2017, p. 109).

17 Estos problemas fueron puestos de presente por los magistrados que salvaron el voto en la Sentencia C-208 de 2005 por la cual se declaró la constitucionalidad del Acto Legislativo 01 de 2003 por vicios de procedimiento en su formación. 
a ningún candidato en particular, se contabilizarán a favor de la respectiva lista para efectos de la aplicación de las normas sobre el umbral y la cifra repartidora, pero no se computarán para la reordenación de la lista" (Art. 20 Acto Legislativo 02 de 2015). Igualmente, la norma aclaró lo que ocurre en los casos en los que el ciudadano marque en el tarjetón el logo del partido y simultáneamente a un candidato. Allí la norma señaló que, en estas circunstancias, se debe contabilizar ese voto en favor del candidato.

No obstante, un aspecto que sí modificó la reforma de equilibrio de poderes fue el relacionado con la silla vacía. En esta nueva reforma se aprovechó la función constituyente para continuar aclarando ciertos aspectos grises de su aplicación, algunos de los cuales habían sido manejados desde las potestades administrativas de las mesas directivas de las corporaciones públicas, por cuenta de la existencia de una omisión legislativa. Por tal motivo, este Acto Legislativo explicó los efectos de la silla vacía para la determinación del quorum de las sillas que no puedan ser reemplazadas.

El mencionado Acto Legislativo implicó una verdadera intervención quirúrgica en lo relativo a la determinación de las condiciones para permitir o no el reemplazo de las sillas vacías por parte de los partidos políticos. De esta forma, esta medida sancionatoria de los partidos pasó de una postura rígida a una postura más flexible, que algunos interpretan como más garantista (Giraldo y Hernández, 2020, p. 38). En efecto, en la reforma política de 2009 la simple vinculación a un proceso penal por delitos "relacionadas con pertenencia, promoción o financiación a/o por grupos armados ilegales, de narcotráfico, delitos contra los mecanismos de participación democrática o de lesa humanidad" daba lugar a la imposibilidad de reemplazar por parte del partido a esa silla dentro del cuerpo representativo.

A partir de la reforma política de 2015 se hace una distinción entre vinculación y condena penal para dar consecuencias jurídicas distintas a la figura. En este orden de ideas, solo hay lugar a decretar la silla vacía, y por ello a imponer el castigo de no reemplazar a un miembro de su bancada, si el Representante o Senador ha sido condenado por un listado de delitos, de manera que se configure la falta absoluta de la curul. Por el contrario, si el miembro del partido ha sido simplemente vinculado al proceso penal, mas no ha sido condenado, entonces se configura una falta temporal que da lugar a un remplazo provisional de esa silla por parte del partido.

Por último, la reingeniería de la silla vacía también sufrió cambios importantes en otros de sus detalles, en la medida en la que el listado de conductas que dan origen a esta sanción se amplió, al determinar la posibilidad de imponer la silla vacía como medida sancionatoria para castigar las condenas por delitos contra la administración pública. Esta modificación seguía el espíritu de lo que se había propuesto originalmente en la reforma política de 2009, y que había sido desojado 
durante el trámite de este Acto Legislativo. Pero este Acto Legislativo continuó dejando por fuera de la discusión, una vez más, la incorporación del voto obligatorio como fórmula para avanzar en la erradicación del clientelismo en Colombia.

\section{Conclusiones}

Como el viejo adagio popular señala el diablo suele estar en los detalles. Infortunadamente la falta de atención del derecho constitucional en Colombia a los detalles en relación con la democracia puede ser un factor explicativo de la vorágine reformista que ha caracterizado estos temas. Una vorágine que ha hecho que hoy en día no podamos reconocer casi nada de la propuesta de la Constitución de 1991 en cuanto a las instituciones de la democracia representativa pasados 30 años de su expedición. Cambios que, como se anotó, continúan siendo insuficientes para fortalecer el eslogan de la democracia tan descuidado en nuestra academia local más allá de su vocación participativa o social.

Se requiere continuar una conversación sobre estas temáticas que tenga en cuenta aspectos como (i) las tensiones que surgen entre la apertura del sistema y su cierre, y entre el personalismo de la democracia parlamentaria a la idea de los partidos fortalecidos de la democracia de partidos; (ii) la regulación de los dispositivos de control que se crean para evitar los problemas del sistema político y electoral para que las normas incluidas en las reformas constitucionales puedan ser puestas en funcionamiento de forma inmediata a su promulgación y no solo ser enunciados sin capacidad de producir consecuencias; y (iii) el examen de los temas que siempre son extirpados de estas reformas como una consecuencia de que el cirujano sea quien reiteradamente se haya practicado la operación a sí mismo.

Hay puntos de inicio importantes para continuar con esa conversación a partir de desarrollos recientes como las propuestas de reforma de la Misión Electoral Especial, el estatuto de la oposición (Ley 1909 de 2018) y el nuevo código electoral que, a la fecha de escribir esta reflexión, aún no termina de ser promulgado como Ley de la República. Sin embargo, el nivel de importancia de estas conversaciones es más bien urgente, si no queremos celebrar en el futuro unas bodas de oro sin que la democracia sea un mero eslogan desprovisto de contenido.

\section{Referencias bibliográficas}

Arévalo, J., Angarita , G. y Jiménez , W. (2013). Reformas Electorales y coherencia ideológica. 1986-2013. Revista mexicana de ciencias políticas y sociales, 58(218), 233-269. Recuperado de http://www.revistas.unam.mx/index.php/rmcpys/ article/view/42670 
Battle, M. y Puyana, J. (2013). Reformas políticas y partidos en Colombia. cuando el cambio es la regla. Politai: Revista de Ciencia Política, 4(7), 73-88.

Bayón, J. C. (2010). Democracia y derechos: problemas fundamentales del constitucionalismo. En M. Carbonell y L. Garcia (eds.), El canon Neo-constitucional (pp. 285-355). España: Trota.

Bobbio, N. (2005). El futuro de la democracia. México: Fondo de Cultura Económica.

Boesten, J. (2014). The generalization of Particularized Trust. Paramilitarism and Structures of Trust In Colombia. Colombia Internacional, (81), 237-265.

Colombia. Congreso de la República. (3 de marzo de 1994). Ley 30 de 1994. Por la cual se dicta el estatuto básico de los partidos y movimientos políticos, se dictan normas sobre su financiación y la de las campañas electorales y se dictan otras disposiciones. Diario Oficial n.․ 41.280.

Colombia. Congreso de la República. (2 de octubre de 2000). Ley 616 de 2000. Por la cual se modifica el artículo 10 de la Ley 130 de 1994. Diario Oficial n. o 44.184.

Colombia. Congreso de la República. (14 de julio de 2009). Acto Legislativo 01 de 2009. Por el cual se modifican y adicionan unos artículos de la Constitución Política de Colombia. Diario Oficial n. 47.410 .

Colombia. Congreso de la República. (14 de julio de 2011). Ley 1475 de 2011. Por la cual se adoptan reglas de organización y funcionamiento de los partidos y movimientos políticos, de los procesos electorales y se dictan otras disposiciones.

Colombia. Congreso de la República. (1 de julio de 2015). Acto legislativo 02 de 2015. Por medio del cual se adopta una reforma de equilibrio de poderes y reajuste institucional y se dictan otras disposiciones. Diario Oficial n. $\stackrel{0}{49560 .}$

Colombia. Congreso de la República. (9 de julio de 2018). Ley 1909 de 2018. Por medio de la cual se adoptan el estatuto de la oposición política y algunos derechos a las organizaciones políticas independientes.

Colombia. Corte Constitucional. (10 de marzo de 2005). Sentencia C-208/05. [MP Clara Inés Vargas Hernández].

Colombia. Corte Constitucional. (23 de junio de 2011). Sentencia C-490/11. [MP Luis Ernesto Vargas Silva].

Cruz, P. M. y Real , G. (2010). Los nuevos escenarios transnacionales y la democracia asimétrica. Revista Jurídicas, 7(2), 13-41. Recuperado de https://dialnet.unirioja. es/servlet/articulo?codigo $=7512662$

Dangond-Gibsone, C. (2012). El Congreso en Colombia. En S. Jost (ed.), 20 años de la Constitución Colombiana. Logros, Retrocesos y Agenda Pendiente (pp. 347-354). Bogotá: Konrad Adenauer. Recuperado de https://www.kas.de/c/document_library/get_file?uuid=f4a5896c-7e2c-c62c-de04-dabfa1241c3d\&groupId=287914

Duque, J. (2011). Redefinición de las reglas de juego: las reformas al sistema electoral colombiano como un caso de volatilidad institucional 1991-2011. 
Papel político, 16(2), 421-460. Recuperado de https://www.redalyc.org/ pdf/777/77722772005.pdf

Farber, D. (2006). Legislative Constitutionalism in a System of Judicial Supremacy. En The Least Examined Branch. Cambridge: Cambridge University Press.

Ferrajoli, L. (2011). Principia Iuris: Teoría del Derecho y de la Democracia (Volumen 3). Madrid: Editorial Trotta.

Franco, B. y Clavijo, B. (2006 ). Impacto de la Reforma Político electoral. Documento de Investigación $n . \stackrel{\circ}{1}$. Bogotá: Universidad del Rosario.

Gaceta del Congreso. (3 de septiembre de 2014). n.o 458. Recuperado de http:// svrpubindc.imprenta.gov.co/senado/index2.xhtml?ent=Senado\&fec=03-09$2014 \&$ num $=458$

García, M. y Revelo, J. (2009). Mayorías sin Democracia. Bogotá: Dejusticia.

Gargarella, R. (2005). Los fundamentos Legales de la Desigualdad. Madrid: Siglo XXI.

Gómez, J. y Hernández, E. (2020). La silla vacía: aplicación jurídica y su consecuencia. Inciso, 22(1), 27-56. Recuperado de https://revistas.ugca.edu.co/index.php/ inciso/article/view/1029

Habermas, J. (2000). Constitutional Democracy: A paradoxical Union of Contradictory Principles?. Political theory, 29(6), 766-781.

Herrera, W. (2011). Derecho Constitucional Colombiano. Bogotá: Temis.

Holguín, J. (2006). La reforma de 2003: La tensión entre abrir y cerrar el sistema político colombiano. En G. Hoskin y M. García (eds.), La Reforma Política de 2003. ¿La salvación de los partidos políticos colombianos?. (pp.33-61). Bogotá: Uniandes.

Hurtado, J. e Hinestroza , L. (2016). La participación democrática en Colombia: Un derecho en evolución. Justicia juris, 12(2), 59-76. Recuperado de http://www. scielo.org.co/pdf/jusju/v12n2/1692-8571-jusju-12-02-00059.pdf

Jaramillo, J. F. (2007 ). La Constitución de 1991, un análisis de sus aportes desde una perspectiva histórica. Pensamiento Jurídico, (20). Recuperado de https://revistas. unal.edu.co/index.php/peju/article/view/38626

Kelsen, H. (2001). La garantía jurisdiccional de la Constitución. Ciudad de México: Universidad Autónoma de México.

Manin, B. (2008). Los principios del Gobierno Representativo. España: Alianza.

Mendes, C. (2013). Conrado Hübner Mendes, Constitutional Courts and Deliberative Democracy, Oxford, Oxford University Press.

Misión Electoral Electoral Especial. (2017). Propuestas reforma politico y electoral. Bogotá: Konrad Adenauer. Recuperado de https://moe.org.co/wp-content/ uploads/2017/04/Libro-Reforrma-completo-2017-1-1.pdf

Molina, C. M. y Perdomo, J. (2005). Derecho constitucional general e instituciones políticas colombianas. Bogotá: Legis. 
Nino, C. (1997). La Constitución de la Democracia Deliberativa. Barcelona: Gedisa.

Nohelen, D. (2009). La Democracia. Instituciones, conceptos y contexto. Medellín: Pontificia Universidad Javeriana.

Padrón, F. (2012). El Fortalecimiento de los Partidos Políticos: ¿Una Tarea Pendiente? En S. Jost, 20 Años de la Constitución Colombiana. Logros, Retrocesos y Agenda Pendiente, Colombia (pp. 241-258). Bogotá: Konrad Adenauer. Recuperado de https://www.kas.de/c/document_library/get_file?uuid=f4a5896c-7e2c-c62cde04-dabfa1241c3d\&groupId=287914

Parra, J. C. (2020). Efectos del voto preferente en el comportamiento electoral de los partidos políticos: el caso de las elecciones al senado de la república de Colombia entre 2006 y 2018. Ratio Juris, 15(30), 186-219. Recuperado de https://publicaciones.unaula.edu.co/index.php/ratiojuris/article/view/699

Pérez, J. (2010). Derecho constitucional colombiano (8ae ed.). Bogotá: Temis.

Pizarro, F. (2001). La atomización partidista en Colombia: el fenómeno de las microempresas electorales. En Gradación o cambio: evaluación del sistema político colombiano (pp. 359-401). Bogotá: IEPRI.

Pzreworski, A. (2010). ¿Que esperar de la democracia?. Madrid: Siglo XXI.

Quinche, M. (2004). Reforma Política y Referendo en Colombia. Bogotá: Universidad del Rosario.

Quinche, M. (2009). La Constitución Política de 1991 y sus reformas. Bogotá: Universidad del Rosario.

Quinche M. (2020). Derecho Constitucional Colombiano. Bogotá: Temis, 2020.

Restrepo, J. C. (11 de junio de 2014). Los cupos indicativos a la luz del derecho presupuestal. Ámbito Jurídico. Recuperado de https://www.ambitojuridico.com/noticias/educacion-y-cultura/los-cupos-indicativos-la-luz-del-derecho-presupuestal

Ruiz, G. (2004). La construcción de la gobernabilidad política en Colombia. En W. Hofmeister (ed.), Reformas Políticas en América Latina (pp. 163-190). Brasil: Kondrad Adenauer.

Salazar, P. (2006). La democracia Constitucional: Una radiografía Teórica. México: Fondo de Cultura Económica.

Sartori, G. ( 2000). Ingenieria Constitucional Comparada. México: Fondo de Cultura Económica.

Uprimny, R. (2012). La Constitución de 1991 como constitución transformadora: ¿Un neoconstitucionalismo fuerte y una democracia débil? En S. Jost (ed.), 20 años de la Constitución Colombiana. Logros, Retrocesos y Agenda Pendiente. (pp. 37-53). Bogotá: Konrad Adenauer. Recuperado de https:// www.kas.de/c/document_library/get_file?uuid=f4a5896c-7e2c-c62c-de04dabfa1241c3d\&groupId=287914 
Uprimny, R. \& García , M. (2005). The Constitutional Court and Social Emancipation in Colombia. En B. d. Soussa (ed.), Democratizing Democracy, Beyond the Liberal Democratic Canon. London: Verso.

Waldron, J. (2006). The Core of the Case Against Judicial Review. The Yale Law Journal.

Wills, L. (2010). el sistema de partidos colombiano después de la reforma de 2003: análisis de los resultados electores legislativos de 2010. EGOB: Revista de Asuntos Públicos (4). Recuperado de https://repositorio.uniandes.edu.co/ handle/1992/7579?show=full

Zuluaga, R. (2008). De la Expectativa al Desconcierto: el Proceso Constituyente Visto por sus Protagonistas. Cali: Pontificia Universidad Javeriana. Seccional Cali. 